\title{
ALCAM is a Novel Cytoplasmic Membrane Protein in TNF- $\alpha$ Stimulated Invasive Cholangiocarcinoma Cells
}

\author{
Poom Adisakwattana ${ }^{1,2}$, Nantana Suwandittakul ${ }^{1}$, Songsak Petmitr ${ }^{3}$, Sopit \\ Wongkham $^{4,5}$, Polkit Sangvanich ${ }^{6}$, Onrapak Reamtong ${ }^{3 *}$
}

\begin{abstract}
Background: Cholangiocarcinoma (CCA), or bile duct cancer, is incurable with a high mortality rate due to a lack of effective early diagnosis and treatment. Identifying cytoplasmic membrane proteins of invasive CCA that facilitate cancer progression would contribute toward the development of novel tumor markers and effective chemotherapy. Materials and Methods: An invasive CCA cell line (KKU-100) was stimulated using TNF- $\alpha$ and then biotinylated and purified for mass spectrometry analysis. Novel proteins expressed were selected and their mRNAs expression levels were determined by real-time RT-PCR. In addition, the expression of ALCAM was selected for further observation by Western blot analysis, immunofluorescent imaging, and antibody neutralization assay. Results: After comparing the proteomics profile of TNF- $\alpha$ induced invasive with non-treated control cells, over-expression of seven novel proteins was observed in the cytoplasmic membrane of TNF- $\alpha$ stimulated CCA cells. Among these, ALCAM is a novel candidate which showed significant higher mRNA- and protein levels. Immunofluorescent assay also supported that ALCAM was expressed on the cell membrane of the cancer, with increasing intensity associated with TNF- $\alpha$. Conclusions: This study indicated that ALCAM may be a novel protein candidate expressed on cytoplasmic membranes of invasive CCA cells that could be used as a biomarker for development of diagnosis, prognosis, and drug or antibody-based targeted therapies in the future.
\end{abstract}

Keywords: Cholangiocarcinoma cell line - cytoplasmic membrane proteins - proteomics - TNF- $\alpha$ - ALCAM

Asian Pac J Cancer Prev, 16 (9), 3849-3856

\section{Introduction}

Cholangiocarcinoma (CCA) is a malignant tumor of the biliary tract that has a high incidence in Southeast Asia, including Thailand (Srivatanakul et al., 2004; Sripa and Pairojkul, 2008). Liver fluke (Opithorchis viverrini) infection, together with nitrosamine consumption are the main risk factors associated with cancer development (Chainuvati et al., 1976; Haswell-Elkins et al., 1992; Prayong et al., 2014; Yothaisong et al., 2014). Numerous studies have attempted to explain the mechanisms of CCA and to discover its biomarkers. CYP39A1, RUNX2 and Oxidized Alpha-1 Antitrypsin have been associated with Cholangiocarcinoma progression (Khenjanta et al., 2014). The ratio of cathepsin B to cystatin $C$ in patient serum was investigated as a marker for CCA diagnosis (Monsouvanh et al., 2014). FXYD3, GPRC5A, CEACAM5, MUC13, EPCAM, TMC5, and EHF were upregulated in intrahepatic CCA using microarray analysis which led to the molecular basic mechanisms of CCA (Subrungruanga et al., 2013). Cytoplasmic membrane proteins are interesting targets that should be further investigated. In previous studies, several cytoplasmic membrane proteins were found to have important roles in the pathogenesis of cancers, eg. growth, invasion, metastasis and dissemination (Han et al., 2009; Wang et al., 2011).

Selectins, integrins and cadherins are surface proteins that have been widely studied in the pathophysiology of several cancers (Faca and Hanash, 2009; Bendas and Borsig, 2012). PSMA (Prostate-Specific Membrane Antigen) is a cytoplasmic membrane protein that was first discovered by monoclonal antibody specific to the cell membrane of a prostate cancer cell line (Wright et al., 1995). This marker had increased expression level in progressive malignant tumors. Human epididymis protein 4 (HE4) is another example of cytoplasmic membrane protein that was overexpressed in patients with ovarian carcinoma and has been proven to be a promising biomarker for certain types of ovarian cancers (Moore et al., 1999; Huhtinen et al., 2009). However, CCA still lacks an effective and specific tumor marker and it has

${ }^{1}$ Department of Helminthology, ${ }^{2}$ Center of Excellence for Antibody Research (CEAR), ${ }^{3}$ Department of Molecular Tropical Medicine and Genetics, Faculty of Tropical Medicine, Mahidol University, ${ }^{6}$ Department of Chemistry, Faculty of Science, Chulalongkorn University, Bangkok, ${ }^{4}$ Department of Biochemistry, ${ }^{5}$ Liver Fluke and Cholangiocarcinoma Research Center, Faculty of Medicine, Khon Kaen University, Khon Kaen, Thailand *For correspondence: onrapak.rea@mahidol.ac.th 
a low responsiveness to anti-cancer drugs (Anderson et al., 2004). Numerous investigations have been conducted on the cytoplasmic membrane of several cancer cells, however no attempt has been made to investigate protein expression on the cytoplasmic membrane of CCA.

In chronic and re-infection of $O$. viverrini, CCA development, and increasing levels of TNF- $\alpha$ have been frequently observed (Mon et al., 2009; Pinlaor et al., 2010). TNF- $\alpha$ is the most important pro-inflammatory cytokine that is involved in cell growth, differentiation, and apoptosis (Cliffe et al., 2007), and promotes invasiveness of cholangiocarcinoma via TNF- $\alpha$ receptor (TNFR) 2 (Tanimura et al., 2005). Tumor necrosis factor receptor-associated factor 6 was highly expressed in lung cancer, which may be related to the lung cancer progression (Zhang et al., 2014). TNF- $\alpha$ in saliva and serum was reported to be associated with oral cancer (Krishnan et al., 2014). TNF- $\alpha$ in patient serum was found to be related to breast cancer tumors, and indicated cancer progression (Tripsianis et al., 2013). Acacia ferruginea extract exhibits tumor inhibitory activity by reducing the level of TNF- $\alpha$ in animals (Sakthivel et al., 2013). Several recent studies have confirmed that TNF- $\alpha$ plays an important role in cancer progression.

In this study, the cytoplasmic membrane protein profile of TNF $\alpha$-induced invasive CCA cell line was analyzed and compared with a non-treated control using mass spectrometry. The mRNA level of the over-expressed novel protein was selected for validation by real time RT-PCR. A novel protein that presented the highest expression was further analyzed by Western blot analysis and immunofluorescence assay. The results presented here may facilitate improvements in the potential novel targets discovery for development of diagnosis, prognosis, and molecular targets for new drugs and antibody therapy in the future.

\section{Materials and Methods}

\section{Culture of cholangiocarcinoma cell line}

Non-invasive CCA cell line, KKU-100, was cultured in Ham F-12 (Gibco, USA), supplemented with $10 \%$ fetal bovine serum (FBS) (Biowest, France), 1X penicillin/ streptomycin (Biowest, France), at $37^{\circ} \mathrm{C}, 5 \% \mathrm{CO}_{2}$ and $\mathrm{N} 2$ balance. The medium was changed every two days. Once the cell growth reached $80 \%$ confluence, it was harvested by digesting with $0.25 \%$ trypsin-EDTA solution (Biowest, France).

\section{MTT assay}

To determine the effect of TNF- $\alpha$ on cell proliferation, a proliferation assay using 3-(4,5-Dimethylthiazol-2-yl)2,5-diphenyltetrazolium bromide (MTT) (Sigma, USA) was performed according to previous experiments with some modifications (Campling et al., 1991). In brief, 100 $\mu \mathrm{l}$ of $7.5 \times 10^{5}$ cells/ml KKU-100 were seeded into 96 well culture plates (Nunc, USA) and then incubated with various concentrations of TNF- $\alpha$ (Prospec, USA) for 16$18 \mathrm{~h}$. After this, $5 \mathrm{mg} / \mathrm{ml}$ MTT (Sigma, USA) was added to each well including one set of wells without cells as a control. The plate was incubated at $37^{\circ} \mathrm{C}$ for $3 \mathrm{~h} 30 \mathrm{~min}$ and then $150 \mu$ DMSO (Amresco, USA) was added to dissolve a formazan crystal. Plates were covered with tinfoil and agitated on a shaking platform for $15 \mathrm{~min}$. The absorbance was measured using a microplate reader (Sunrise Basic Tecan,Austria) at $590 \mathrm{~nm}$ with a reference filter at $620 \mathrm{~nm}$.

\section{Matrigel invasion assay}

Matrigel invasion assay was performed according to the science advisory board website (www.scienceboard. net/resources/protocols). In detail, the matrigel (BD Bioscience, UK) was thawed on ice overnight and diluted to $1 \mathrm{mg} / \mathrm{ml}$ in cold serum-free Ham-F12 (Gibco, USA). A $100 \mu \mathrm{l}$ of matrigel was applied into chamber of 24-well transwell (Corning Incoporated, USA) and incubated at $37^{\circ} \mathrm{C}$ for $4-5 \mathrm{~h}$ for gelling. Next, $100 \mu \mathrm{l}$ of $1 \mathrm{x} 106 \mathrm{cells} / \mathrm{ml}$ KKU-100 was seeded into the transwell and subsequently TNF- $\alpha$ (Prospec, USA) was added at a final concentration of $0.1,1,10$, and $100 \mathrm{ng} / \mathrm{ml}$. The lower chamber of the transwell was filled with $650 \mu$ of Ham-F12 (Gibco, USA) containing $1 \% \mathrm{FBS}$ and $1 \mathrm{X}$ penicillin/streptomycin (Biowest, France) and subsequently incubated at $37^{\circ} \mathrm{C}$ for $24 \mathrm{~h}$. For detection, cells were fixed with $3.7 \%$ formaldehyde in 1X PBS for $2 \mathrm{~min}$ and then permeabilized by $100 \%$ methanol at room temperature for 20 minutes. The transwell was washed with 1X PBS twice and stained with Giemsa (Sigma, USA) for 15 minutes. After washing with $1 \mathrm{X}$ PBS, non-invaded cells on the top of the transwell was removed by a cotton swab and invading cells were counted under a light microscope (Olympus, USA). Time-course analysis was performed by choosing optimal concentration $(10 \mathrm{ng} / \mathrm{ml})$ of TNF- $\alpha$ (Prospec, USA) and the number of invading cells were counted at different time points; $0,6,12,24$ and $48 \mathrm{~h}$.

\section{Isolation of cytoplasmic membrane}

Cytoplasmic membrane of KKU-100 cell line was extracted using cell surface protein isolation kit (Thermo scientific, USA). KKU-100 was cultured in $75 \mathrm{~cm}^{2}$ culture flask (Corning, USA) until reaching 70-80\% confluence and then incubated with or without $10 \mathrm{ng} / \mathrm{ml} \mathrm{TNF}-\alpha$ (Prospec, USA) for $24 \mathrm{~h}$. After incubation, KKU-100 cells were labeled with thermo science EZ-link sulfoNHS-SS-Biotin (Thermo, USA). The labeled cells were disrupted with a mild detergent and the labeled proteins were isolated with Neutravidin agarose resin (Thermo, USA). The bound proteins were released by incubation with SDS-PAGE sample buffer containing $50 \mathrm{mM}$ DTT (GE Healthcare, UK) and used for further experiments.

\section{Mass spectrometry}

Isolated cytoplasmic membrane proteins of TNF- $\alpha$ treated and non-treated cells were size-separated on $12 \%$ SDS-PAGE, and subsequently stained with coomassie brilliant blue G250 solution (Biorad, USA). The gels were cut along the length into equal small cubes (Figure 1) and then destained with destaining solution $(50 \mathrm{mM}$ $\mathrm{NH} 4 \mathrm{HCO} 3,50 \%(\mathrm{~V} / \mathrm{V})$ acetonitrile $(\mathrm{ACN}))$. The gels containing proteins were treated with $5 \mathrm{mM}$ dithiothreitol (DTT) (GE Healthcare, UK) and alkylated with $250 \mathrm{mM}$ iodoacetamide (IAM) (GE Healthcare, UK). Then the gels 
were incubated in the dark for $30 \mathrm{~min}$, dehydrated with 200 $\mathrm{ml} \mathrm{ACN}$ and digested with trypsin $(100 \mathrm{ng} / \mathrm{ml})$ (Sigma, USA). After tryptic digestion, the peptides were extracted from gel using $50 \%$ (V/V) ACN and dried by vacuum evaporator (Labconco, USA). Peptides were resuspended with $0.1 \%$ formic acid and then analyzed by MicroToF Q II mass spectrometer (Bruker; Bremen, Germany). The front end of the mass spectrometer was coupled with an Ultimate 3000 nano-LC system (Dionex; Surrey, UK). After separation, peptide fractions were automatically infused to mass spectrometer. The LC-MS/MS raw data files were processed and converted into the mascot generic file (.mgf) using DataAnalysisTM software, version 3.4. The .mgf files were searched using Mascot version 2.4.1 (Matrix Science, London, UK) against the SwissProt database (15 July 2014), which contained 546,000 sequence entries. Homo sapiens (human), containing 20,210 sequences, was set for the taxonomy filter. Missed cleavage was set to 1 . Peptide tolerance and tandem MS

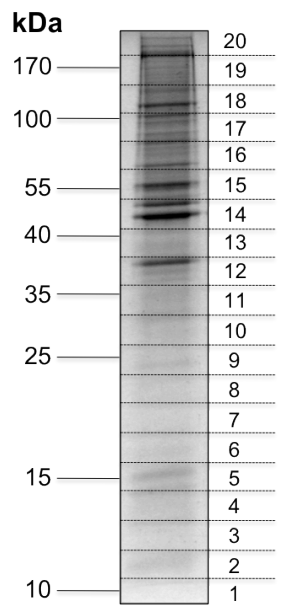

Figure 1. Enriched Cytoplasmic Membrane Fraction was Separated in $12 \%$ SDS-PAGE. The gel was excised into 20 pieces equal size for mass spectrometry analysis. Protein standard marker 10-170 kDa (Thermo) was indicated on the left hand side tolerance were set to 1.2 Da and 0.6 Da, respectively. Fixed modification was set to cysteine carbamidomethylation and variable modification included methionine oxidation. The receiving proteins were compared between TNF- $\alpha$ treated and non-treated cells using exponentially modified protein abundance index (emPAI) ratio (Ishihama et al., 2005). All reported emPAI values were the mean of three MS analysis replications. Protein hits from the MASCOT search with a minimum of at least 2 peptides and a minimum score of 20 were filtered as true identification for further analysis. The novel cytoplasmic membrane proteins with over-expression were selected for further validation.

\section{SYBR Real Time RT-PCR}

The total RNA from TNF- $\alpha$ treated and nontreated KKU-100 cells were extracted using the TriZol reagent (Invitrogen, USA) according to manufacturer's instructions. $5 \mu \mathrm{g}$ of RNA were treated with DNase I (Thermo, USA) to eliminate any contaminating genomic DNA. After that, 1st strand cDNAs were constructed from the $1 \mu \mathrm{g}$ DNA-free RNA template using $1 \mathrm{st}$ strand construction kit (Thermo, USA) according to manufacturer's instructions. Level of gene transcribes was determined by SYBR real-time PCR. The amplification mixture was composed of $2 \mu \mathrm{l}$ of 1 st strand cDNA, 1X SsoFastTM Evagreen ${ }^{\circledR}$ Supermix (Biorad, USA), and $500 \mathrm{nM}$ of each forward and reverse primers. Primers for amplification of gene targets were designed using the Primer3 program (http://frodo.wi.mit.edu/primer3/). The sequences of primers are described in Table 1. Amplification was performed with LightCycler ${ }^{\circledR} 480$ system (Roche, USA) with cycles of $95^{\circ} \mathrm{C}$ for 3 min and 45 cycles of $95^{\circ} \mathrm{C}$ for $30 \mathrm{sec}$ and $60^{\circ} \mathrm{C}$ for $10 \mathrm{sec}$. All samples were analyzed in duplicate. Expression level of each gene target was normalized with the housekeeping gene (Glyceraldehyde 3-phosphate dehydrogenase (GAPDH)) using the formula of $2^{-\Delta C t}$ (Livak and Schmittgen, 2001). The fold change of transcription was calculated by

Table 1. Primers of SYBR Real-time PCR for Detection of Gene Expression Profile in KKU-100 Cell-line

\begin{tabular}{|c|c|c|c|c|}
\hline Gene & Accession no. & Product size (bp) & Primers (5'-3') & Primer length (nt) \\
\hline \multirow[t]{2}{*}{ ALCAM } & \multirow[t]{2}{*}{ NM_001627.3 } & \multirow[t]{2}{*}{191} & 5'CCCCAGAGGAATTTTTGTTT3' & 20 \\
\hline & & & 5’TCCACTTGGGTTTAAGGACA3' & 20 \\
\hline \multirow[t]{2}{*}{ DAF } & \multirow[t]{2}{*}{ M31516.1 } & \multirow[t]{2}{*}{194} & 5'GCAGTCAATGGTCAGATATTGAAG3' & 24 \\
\hline & & & 5'ATTCTGAAGGCAAGTTAGTTTTGG3' & 24 \\
\hline \multirow[t]{2}{*}{ TMM33 } & \multirow[t]{2}{*}{ NM_001261135.1 } & \multirow[t]{2}{*}{196} & 5’TGCCACAGTTTTTATGCTTTTTAG3' & 24 \\
\hline & & & 5'CTGGAGACAAAGTCTTCTCACAAA3' & 24 \\
\hline \multirow[t]{2}{*}{ PGRC2 } & \multirow[t]{2}{*}{ AJ002030.1 } & \multirow[t]{2}{*}{161} & 5’ATGATCTCTCAGATTTGAATGCAG3' & 24 \\
\hline & & & 5’ATCCTGTTTATTGTGATCCTTGGT3’ & 24 \\
\hline \multirow[t]{2}{*}{ PLAK } & \multirow[t]{2}{*}{ NM_021991.2 } & \multirow[t]{2}{*}{184} & 5' ACATACACCTACGACTCGGGTATC3' & 24 \\
\hline & & & 5'CTGTTGTGGACATCTGGTACTCC3' & 23 \\
\hline \multirow[t]{2}{*}{ TMED9 } & \multirow[t]{2}{*}{ NM_017510.4 } & \multirow[t]{2}{*}{178} & 5'CAGGTTCACTTTCACTTCCCATAC3' & 24 \\
\hline & & & 5'CTGCAACTCACTCAACTTGTCTTT3' & 24 \\
\hline \multirow[t]{2}{*}{ PDIA3 } & \multirow[t]{2}{*}{ NM_005313.4 } & \multirow[t]{2}{*}{148} & 5’AGCTCAGCAAAGACCCAAAT3' & 20 \\
\hline & & & 5'CGGCCACCTTCATATTTCTT3' & 20 \\
\hline \multirow[t]{2}{*}{ TFR1 } & \multirow[t]{2}{*}{ X01060.1 } & \multirow[t]{2}{*}{196} & 5'AATGAAAATTCATATGTCCCTCGT3' & 24 \\
\hline & & & 5'CCAGGTAAACAAGTCTACCGTTCT3' & 24 \\
\hline \multirow[t]{2}{*}{ AT1B1 } & \multirow[t]{2}{*}{ NM_001677.3 } & \multirow[t]{2}{*}{177} & 5'GACTGAAATTTCCTTTCGTCCTAA3' & 24 \\
\hline & & & 5'CCTCGTTCATGATTAAAGTCTCCT3' & 24 \\
\hline \multirow[t]{2}{*}{ GAPDH } & \multirow[t]{2}{*}{ XM005253678 } & \multirow[t]{2}{*}{150} & 5’GCATCCTGGGCTACACTGAG’3 & 20 \\
\hline & & & 5’TGCTGTAGCCAAATTCGTTG3’' & 20 \\
\hline
\end{tabular}


comparison TNF- $\alpha$ treatment with non-treated control using the formula of $2^{-\Delta \Delta C t}$.

\section{Western blot analysis}

In this study, the activated leukocyte cell adhesion molecule (ALCAM) was significantly up-regulated in TNF- $\alpha$ treated KKU-100 cells. ALCAM protein expression level was evaluated with western blot analysis. KKU-100 cells were treated with or without TNF- $\alpha$ as mentioned above and then proteins were extracted by homogenizing in RIPA buffer (ingredient). Protein concentration was determined by Coomassie (Bradford) protein assay kit (Thermo, USA) according to manufacturer's instructions. The protein extracts were separated by $12 \%$ SDS-PAGE and electrically transferred onto PVDF membrane (Pall, USA). The membrane was blocked with $5 \%$ skimmed milk and then incubated with mouse anti-human ALCAM antibody (Biolegend, USA) or mouse anti-human $\beta$-actin antibody (Cell signaling, USA) at $4^{\circ} \mathrm{C}$ for $16-18 \mathrm{~h}$. The following day, the membrane was washed 3 times with 1X PBST and then incubated with goat anti-mouse immunoglobulin (Ig) antibody conjugated with horseradish peroxidase (HRP) (Southern Biotech, USA). After washing, the membrane was incubated with chemiluminescent substrate (Pierce, USA) and the signal was monitored by ImageQuant LAS4000 mini (GE Healthcare, UK). Protein band intensity was determined by the ImageJ program (http://imagej.nih.gov/ij/) and then normalized with $\beta$-actin. The fold change was calculated by comparing TNF- $\alpha$ treated and non-treated KKU-100 cells. The experiment was independently performed in triplicate.

\section{Immunofluorescence}

$1 \times 10^{5}$ cells of KKU-100 cells were placed on sterile $1.5 \mathrm{~cm}$ diameter slides cover slips (Thermo, USA) in 24-well culture plate (Nunc, USA) containing complete medium. Cells were incubated at $37^{\circ} \mathrm{C}, 5 \% \mathrm{CO}_{2}$ for $6 \mathrm{~h}$ to allow adherence and then treated with $10 \mathrm{ng} / \mathrm{ml} \mathrm{TNF}-\alpha$ for 16-18 h. Non-treated cells were used as control. Cells were fixed with $4 \%$ paraformaldehyde for $15 \mathrm{~min}$ at $4^{\circ} \mathrm{C}$ and subsequently blocked for $1 \mathrm{~h}$ with $5 \%$ bovine serum albumin (BSA) at room temperature. Mouse anti-human ALCAM or mouse anti-human $\beta$-actin at a dilution of $1: 100$ was applied on the cells and incubated for $16-18 \mathrm{~h}$ at $4^{\circ} \mathrm{C}$. Next, cells were incubated with 1:200 goat anti-mouse Ig antibody conjugated with FITC for $1 \mathrm{~h}$. Counterstaining of cell nuclei was performed by incubating with $1 \mu \mathrm{g} / \mathrm{ml}$ of 4', 6-diamidino-2-phenylindole (DAPI) (Sigma, USA). The fluorescent image was analyzed using a fluorescent microscope (Olympus, USA).

\section{Antibody neutralization assay}

$1 \times 10^{5}$ cells of KKU-100 were seeded into transwell coated with matrix gel and then incubated with anti-human ALCAM antibody (R\&D system, USA) at different concentrations, for $1 \mathrm{~h}$ at $37^{\circ} \mathrm{C}$. Next, $10 \mathrm{ng} / \mathrm{ml}$ of TNF- $\alpha$ was applied and further incubated for $16-18 \mathrm{~h}$, at $37^{\circ} \mathrm{C}$. Invading cells were stained with Giemsa and counted under light microscope (Olympus, USA) to determine \% inhibition. Irrelevant antibody (IgG) was used as treatment control.

\section{Data analysis}

All sets of data were collected and analyzed for statistical significance using non-parametric t-test with a $p$ value of $<0.05$ considered statistically significant. All results show the mean $\pm \mathrm{SD}$ of triplicate determinations in two different experiments.

\section{Results}

TNF- $\alpha$ does not induce proliferation of cholangiocarcinoma cell line but enhances cell invasion

According to the determination of TNF- $\alpha$ effect on proliferation of CCA, our results showed that TNF- $\alpha$ did not induce proliferation of KKU-100 cell line even after increasing dosage. The proliferation rate was equal when treated with TNF- $\alpha$ at the concentration of $0,0.1$ and $10 \mathrm{ng} / \mathrm{ml}$ but significantly decreased with higher concentration (100, 1,000 and 2,000 ng/ml) (Figure 2A). Not only cell proliferation was investigated in this study, the effect of TNF- $\alpha$ on CCA cell line invasion was also determined. Treatment of KKU-100 (non-invasive) cells with different doses of TNF- $\alpha(0.1,1,10$ and $100 \mathrm{ng} / \mathrm{ml})$ found that KKU-100 cells invaded through the matrix gel-coated membrane depended on dosage. Cell invasion initially occurred at TNF- $\alpha$ the concentration of $1 \mathrm{ng} / \mathrm{ml}$, while the highest number of invading KKU-100 cells was at the concentration of $10 \mathrm{ng} / \mathrm{ml}$ with significant difference $(p=0.023)$ when compared to control (Figure 2B). However, further treating KKU-100 cells with TNF- $\alpha$ at $100 \mathrm{ng} / \mathrm{ml}$ decreased level of cell invasion. The time-

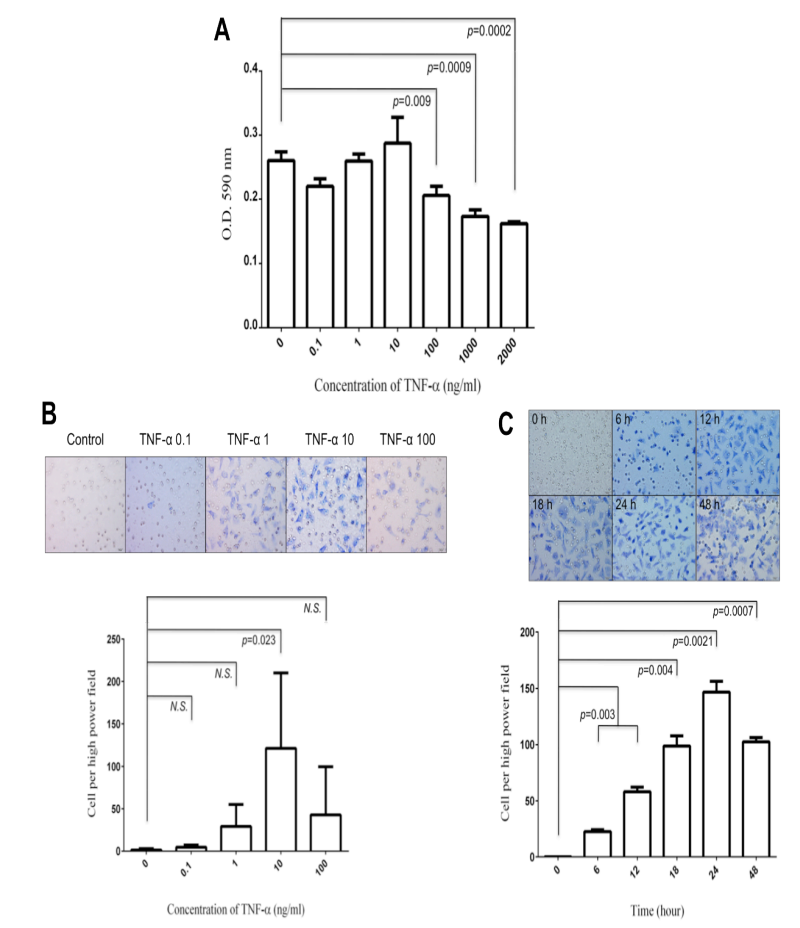

Figure 2. Analysis of TNF- $\alpha$ on Proliferation of KKU100 Cell Line. (A) TNF- $\alpha$ at $0.1,1,10,100,1000$ and 2000 $\mathrm{ng} / \mathrm{ml}$ were investigated the effect on proliferation fusing MTT assay. (B) TNF- $\alpha$ stimulated invasiveness of KKU-100 with dose-dependence. (C) Time-course analysis was performed by treating KKU-100 cell line with $10 \mathrm{ng} / \mathrm{ml}$ at different time points 
A Novel Cytoplasmic Membrane Protein in TNF- $\alpha$ Stimulated Cholangiocarcinoma Cells Table 2. Up-regulated Novel Proteins in the TNF-a Induced and Non-induced of Cholangiocarcinoma Cytoplasmic Membrane

\begin{tabular}{|c|c|c|c|c|c|c|}
\hline \multirow[t]{2}{*}{ Accession } & \multirow[t]{2}{*}{ Protein } & \multirow{2}{*}{$\begin{array}{l}\text { Subcellular } \\
\text { location }\end{array}$} & \multirow[t]{2}{*}{ Mass } & \multirow[t]{2}{*}{$\mathrm{pI}$} & \multicolumn{2}{|c|}{ emPAI value } \\
\hline & & & & & $\begin{array}{l}\text { Non TNF- } \alpha \\
\text { induction }\end{array}$ & $\begin{array}{l}\text { TNF- } \alpha \\
\text { induction }\end{array}$ \\
\hline CD166_HUMAN & Alcam/CD166 antigen & Cell membrane & 65745 & 5.92 & ND* & $0.06 \pm 0.02$ \\
\hline DAF_HUMAN & Complement decay-accelerating factor & Cell membrane & 42400 & 7.79 & ND* & $0.09 \pm 0.05$ \\
\hline TMM33_HUMAN & Transmembrane protein 33 & Cell membrane & 28302 & 9.75 & ND* & $0.13 \pm 0.06$ \\
\hline PGRC2_HUMAN & $\begin{array}{l}\text { Membrane-associated progesterone } \\
\text { receptor component } 2\end{array}$ & Cell membrane & 23861 & 4.76 & ND* & $0.16 \pm 0.03$ \\
\hline PLAK_HUMAN & Junction plakoglobin & Cell membrane & 82434 & 5.75 & ND* & $0.13 \pm 0.17$ \\
\hline TMED9_HUMAN & $\begin{array}{l}\text { Transmembrane emp } 24 \\
\text { domain-containing protein } 9\end{array}$ & Cell membrane & 27374 & 7.82 & ND* & $0.14 \pm 0.03$ \\
\hline PDIA3_HUMAN & Protein disulfide-isomerase A3 & Cell membrane & 57146 & 5.98 & ND* & $0.14 \pm 0.25$ \\
\hline
\end{tabular}

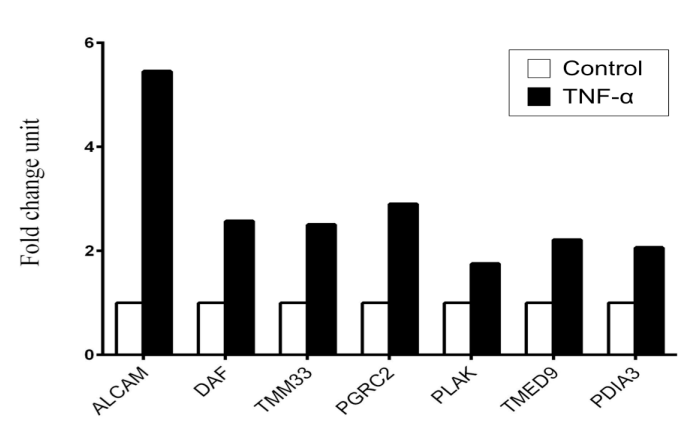

Figure 3. SYBR Green Real-Time PCR for Validating Target Gene Expression. Fold change unit was calculated by comparison TNF- $\alpha$ treated- and non-treated cells. GAPDH was used as a control to normalize the expression level of gene targets

dependence of cancer cell invasion was also explored. KKU-100 cells were incubated with TNF- $\alpha(10 \mathrm{ng} / \mathrm{ml})$ at different time points $(0,6,12,24$, and $48 \mathrm{~h})$. The results showed that KKU-100 increasingly invaded the matrix gel coated membrane related to time of incubation. At $24 \mathrm{~h}$ the highest number of cell invasion was found ( $\mathrm{p}=0.0021$ ), which was used as the optimal time for further study (Figure 2C). When prolonging incubation period to 48 $\mathrm{h}$, we found that the number of invading cells decreased compared to $24 \mathrm{~h}$.

TNF- $\alpha$ induced changing of cytoplasmic membrane protein profiles of cholangiocarcinoma cell line

After treating the KKU-100 cell line with TNF- $\alpha$ $10 \mathrm{ng} / \mathrm{ml}$ for $24 \mathrm{~h}$, enriched fractions of TNF- $\alpha$ induced and non-induced cytoplasmic membrane protein were isolated and further separated in 12\% SDS-PAGE. The entire lane was excised into twenty pieces (Figure 1). Each gel piece underwent tryptic digestion and was analyzed by mass spectrometry. Only proteins identified in all three MS analysis replications were reported. Proteomic analysis identified a total of 1,174 proteins, and 973 proteins $(82.8 \%)$ were common in both noninduced and in the TNF- $\alpha$ induced cholangiocarcinoma cell line. Seven novel proteins were expressed in TNF- $\alpha$ induced cholangiocarcinoma cell line, and were selected for further analysis.

mRNA expression of novel cytoplasmic membrane proteins of TNF- $\alpha$ induced cholangiocarcinoma cell line

The levels of the 7 novel mRNAs: activated leukocyte

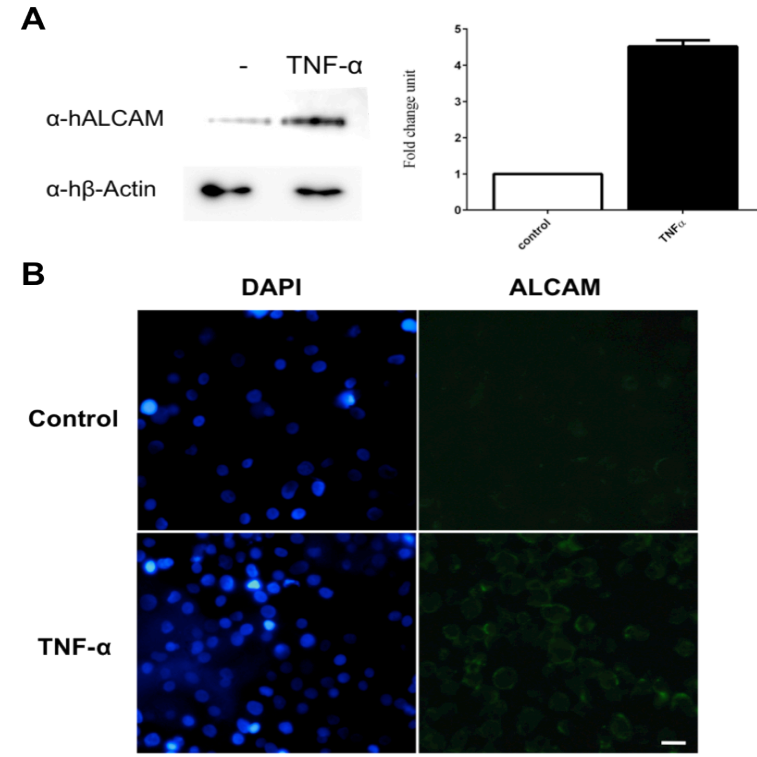

Figure 4. Western Blot and Immunofluorescence Analysis of ALCAM. (A) Western blot analysis of ALCAM using anti-human ALCAM ( $\alpha$-hALCAM) presented that ALCAM was increasingly expressed in TNF- $\alpha$ induced KKU100. (B) Immunofluorescence of KKU-100 using anti-human ALCAM and DAPI (DNA binding compound) in the cell treated with $10 \mathrm{ng} / \mathrm{ml} \mathrm{TNF-} \alpha$ comparing to non-treated control (Control)

cell adhesion molecule (ALCAM/CD166), complement decay-accelerating factor (DAF), transmembrane protein 33 (TMM33), membrane-associated progesterone receptor component-2 (PGRC2), junction plakoglobin (PLAK), transmembrane emp24 domain-containing protein 9 (TMED9), and protein disulfide isomerase family A member 3 (PDIA3) (Table 2) in TNF- $\alpha$ induced and noninduced CCA cell line were analyzed by real time RT-PCR. The expression of these mRNA were 5.45, 2.76, 2.50, 2.26, 1.75 and 2.50 fold, respectively (Figure 3 ).

Localization of ALCAM on the cytoplasmic membrane of cholangiocarcinoma cell line

Immunofluorescence was performed to confirm the expression level and location of ALCAM in KKU-100 cell line. Non-permeable cells were incubated with anti-human ALCAM antibodies and probed with secondary antibody conjugated with FITC. Results indicate that the higher fluorescent intensity presented on the surface of TNF- $\alpha$ induced KKU-100 cells compared to non-treated control 


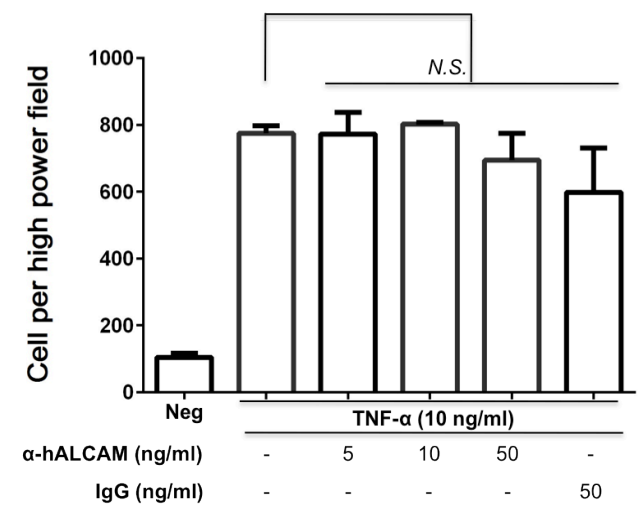

Figure 5. Inhibitory Effect of ALCAM Neutralizing Antibody on Invasion of TNF- $\alpha$ Treated KKU-100 Cell Line. The KKU-100 cells were blocked by neutralizing antibody or IgG (control) before TNF- $\alpha$ treatment to investigate the inhibition of cell invasion

(Figure 4), confirmed the effect of TNF- $\alpha$ on induction of ALCAM expression on cytoplasmic membrane of CCA cell line.

Inhibition of ALCAM on surface membrane of cholangiocarcinoma cell line

There is no data available to suggest the role of ALCAM in progressive CCA. Therefore, this experiment aimed to investigate the function of ALCAM in facilitating invasion of CCA cell line using human ALCAM neutralizing antibody. However, no inhibitory effect of human ALCAM neutralizing antibody against TNF- $\alpha$ treated KKU-100 cells invasion was observed (Figure 5). This indicates that ALCAM may not play a role in cell invasion in TNF- $\alpha$ treated KKU-100 cells line.

\section{Discussion}

Cholangiocarcinoma remains an incurable cancer because of a lack of tumor markers and the disease's low responsiveness to anti-cancer drugs (Anderson et al., 2004; Srimunta et al., 2012). Although novel markers have been identified and evaluated in the past decades they remain insufficient. Determination of cytoplasmic membrane proteome may be a promising step towards the development of reliable diagnosis, prognosis, and drug design. Cytoplasmic membrane proteomics of several cancers have been identified (Kischel et al., 2008; Liu et al., 2010; Ziegler et al., 2014), but not in CCA. In this study, 7 novel cytoplasmic membrane proteins in TNF- $\alpha$ inducible CCA cell line were detected by nanoLC/MS/MS. Initially, a proliferation assay with different concentration of TNF- $\alpha$ was performed to verify the effect of TNF- $\alpha$ on cell proliferation. The results showed that TNF- $\alpha$ did not affect cell proliferation but suppressed cell growth at high concentration ( $>100 \mathrm{ng} / \mathrm{ml})$. Previous studies of other cancer cell lines have suggested that TNF- $\alpha$ is a pleiotrophic cytokine with dual roles in both cancer cell proliferation and apoptosis (Falkensammer et al., 2006; Kondo et al., 2008). However, the irresponsiveness of TNF- $\alpha$ on CCA cell line (KKU-100) proliferation is still unclear and needs further investigation. Additionally, TNF- $\alpha$ can facilitate cancer cell invasion and has been investigated in breast cell lines (Ryu et al., 2011) and glioma cell lines (Bao et al., 2014). The results of our invasion assay supported that TNF- $\alpha$ also affected invasiveness of CCA cell line with dose- and time dependence. This may be because TNF- $\alpha$ regulated the downstream signal proteins to mediate the cancer progression (Techasen et al., 2014). The mass spectrometry results showed that several proteins were upregulated in TNF- $\alpha$ treated CCA cell line. Among these, only 7 novel proteins over-expression were observed in the TNF- $\alpha$ treated CCA cell line (ALCAM, DAF, TMM33, PGRC2, PLAK, TMED9 and PDIA3). ALCAM was the fascinating target that highly expressed both mRNA and protein and has not been reported in CCA. ALCAM/ CD166 activated the leukocyte cell adhesion molecule that plays important roles in leukocyte migration. Overexpression of ALCAM has been reported as prognostic biomarker in several cancers, including breast (Burkhardt et al., 2006), prostate (Jiao et al., 2012), colon (Hansen et al., 2013), and pancreatic (Tachezy et al., 2012). Jiao et al, suggested that up-regulation of ALCAM was associated with severe clinical manifestations including metastasis and castration resistant prostate cancers (CRPC) (Jiao et al., 2012). Likewise, they demonstrated that ALCAM was highly expressed on the surface of prostate stem/ progenitor and cancer initiating cells (Jiao et al., 2012). In melanoma, pancreatic- and prostate cancers, up-regulation of ALCAM is associated with invasion and metastasis (Jannie et al., 2012; Fujiwara et al., 2014; Hansen et al., 2014). Our findings support these previous studies - ALCAM up-regulated both mRNA and protein levels when the CAA cell line was induced to invasive character. This may imply that ALCAM has a role associated with the invasion of CCA, similar to prostate cancer (Jiao et al., 2012). The result of immunofluorescence found that ALCAM stained on the cytoplasmic membrane of CCA cell line correlated with increasing intensity in the cell treated with TNF- $\alpha$. The location and increasing the expression of ALCAM in CCA cell line may suggest its roles in cell migration and invasion as found in other cancers (breast and pancreatic cancer) (Davies and Jiang, 2010; Fujiwara et al., 2014). In melanoma, silencing ALCAM expression in high-ALCAM expressed cell line a showed reduction of cell motility and invasiveness (Jannie et al., 2012). Moreover, blocking ALCAM with single-chain antibody inhibited invasiveness of breast cancer (Wiiger et al., 2010). On the contrary, our results showed that blocking ALCAM with the antibody did not affect invasion of CCA even when increasing to very high concentrations. However, knockout of ALCAM gene did not interfere with prostate cancer progression (Jiao et al., 2012), which implies that the role of ALCAM in cancer cell invasion may depend on the type of cancer. As mentioned in prostate cancer, ALCAM does not play role in cell invasion but may be a promising marker for prostate stem/progenitor and cancer initiating cells (Jiao et al., 2012). The potential of ALCAM as a biomarker of stem/progenitor and cancer initiating CCA cells, including the role of the protein in CCA homeostasis needs to be investigated further.

In conclusion, seven novel cytoplasmic membrane proteome of invasive CCA were first discovered using 
mass spectrometry. Among these candidates, the overexpression of ALCAM was identified as the biomarker associated with invasiveness of TNF- $\alpha$ inducible KKU-100 cell line. This suggests that ALCAM might be a potential target for the development of diagnosis, prognosis, and anti-cancer drug against CCA in the future.

\section{Acknowledgements}

This work is supported by grant from Thailand Research Fund (TRF) in the program of initiative career development through Dr. Poom Adisakwattana (MRG5480127). We thank Glad Rotaru of the Office of Research Services, Faculty of Tropical Medicine, Mahidol University for proofreading and correcting this manuscript.

\section{References}

Abraham SC, Lee JH, Hruban RH, et al (2003). Molecular and immunohistochemical analysis of intraductal papillary neoplasms of the biliary tract. Hum Pathol, 34, 902-10.

Anderson CD, Pinson CW, Berlin J, et al (2004). Diagnosis and treatment of cholangiocarcinoma. Oncologist, 9, 43-57.

Balkwill F (2009). Tumour necrosis factor and cancer. Nat Rev Cancer, 9, 361-71.

Bao C, Namgung H, Lee J, et al (2014). Daidzein suppresses tumor necrosis factor-alpha induced migration and invasion by inhibiting hedgehog/Gli1 signaling in human breast cancer cells. J Agric Food Chem, 62, 3759-67.

Bendas G, Borsig L (2012). Cancer cell adhesion and metastasis: selectins, integrins, and the inhibitory potential of heparins. Int J Cell Biol, 2012, 676731.

Burkhardt M, Mayordomo E, Winzer KJ, et al (2006). Cytoplasmic overexpression of ALCAM is prognostic of disease progression in breast cancer. J Clin Pathol, 59, 403-9.

Campling BG, Pym J, Baker HM, et al (1991). Chemosensitivity testing of small cell lung cancer using the MTT assay. $\mathrm{Br} \mathrm{J}$ Cancer, 63, 75-83.

Chainuvati T, Paosawadhi A, Sripranoth M, et al (1976). Carcinoma of the cystic duct associated with opisthorchiasis. Southeast Asian J Trop Med Public Health, 7, 482-6.

Cliffe LJ, Potten CS, Booth CE, et al (2007). An increase in epithelial cell apoptosis is associated with chronic intestinal nematode infection. Infect Immun, 75, 1556-64.

Davies S, Jiang WG (2010). ALCAM, activated leukocyte cell adhesion molecule, influences the aggressive nature of breast cancer cells, a potential connection to bone metastasis. Anticancer Res, 30, 1163-8.

Faca VM, Hanash SM (2009). In-depth proteomics to define the cell surface and secretome of ovarian cancer cells and processes of protein shedding. Cancer Res, 69, 728-30.

Falkensammer C, Johrer K, Gander H, et al (2006). IL-4 inhibits the TNF-alpha induced proliferation of renal cell carcinoma (RCC) and cooperates with TNF-alpha to induce apoptotic and cytokine responses by RCC: implications for antitumor immune responses. Cancer Immunol Immunother, 55, 1228-37.

Franceschini A, Szklarczyk D, Frankild S, et al (2013). STRING v9.1: protein-protein interaction networks, with increased coverage and integration. Nucleic Acids Res, 41, 808-15.

Fujiwara K, Ohuchida K, Sada M, et al (2014). CD166/ALCAM expression is characteristic of tumorigenicity and invasive and migratory activities of pancreatic cancer cells. PLoS One, 9, 107247.
Furubo S, Harada K, Shimonishi T, et al (1999). Protein expression and genetic alterations of p53 and ras in intrahepatic cholangiocarcinoma. Histopathology, 35, 230-40.

Hallermalm K, Seki K, Wei C, et al (2001). Tumor necrosis factor-alpha induces coordinated changes in major histocompatibility class I presentation pathway, resulting in increased stability of class I complexes at the cell surface. Blood, 98, 1108-15.

Han ZD, Bi XC, Qin WJ, et al (2009). CD147 expression indicates unfavourable prognosis in prostate cancer. Pathol Oncol Res, 15, 369-74.

Hansen AG, Arnold SA, Jiang M, et al (2014). ALCAM/CD166 is a TGF-beta-responsive marker and functional regulator of prostate cancer metastasis to bone. Cancer Res, 74, 1404-15.

Hansen AG, Freeman TJ, Arnold SA, et al (2013). Elevated ALCAM shedding in colorectal cancer correlates with poor patient outcome. Cancer Res, 73, 2955-64.

Haswell-Elkins MR, Sithithaworn P, Elkins D (1992). Opisthorchis viverrini and cholangiocarcinoma in Northeast Thailand. Parasitol Today, 8, 86-9.

Huhtinen K, Suvitie P, Hiissa J, et al (2009). Serum HE4 concentration differentiates malignant ovarian tumours from ovarian endometriotic cysts. Br J Cancer, 100, 1315-9.

Ishihama Y, Oda Y, Tabata T, et al (2005). Exponentially modified protein abundance index (emPAI) for estimation of absolute protein amount in proteomics by the number of sequenced peptides per protein. Mol Cell Proteomics, 4, 1265-72.

Jannie KM, Stipp CS, Weiner JA (2012). ALCAM regulates motility, invasiveness, and adherens junction formation in uveal melanoma cells. PLoS One, 7, 39330.

Jiao J, Hindoyan A, Wang S, et al (2012). Identification of CD166 as a surface marker for enriching prostate stem/progenitor and cancer initiating cells. PLoS One , 7, 42564.

Kischel P, Guillonneau F, Dumont B, et al (2008). Cell membrane proteomic analysis identifies proteins differentially expressed in osteotropic human breast cancer cells. Neoplasia, 10, 1014-20.

Kondo J, Sato F, Kusumi T, et al (2008). Claudin-1 expression is induced by tumor necrosis factor-alpha in human pancreatic cancer cells. Int J Mol Med, 22, 645-9.

Livak KJ, Schmittgen TD (2001). Analysis of relative gene expression data using real-time quantitative PCR and the 2(-Delta Delta C(T) Method. Methods, 25, 402-8.

Liu X, Zhang M, Go VL, et al (2010). Membrane proteomic analysis of pancreatic cancer cells. J Biomed Sci, 17, 74.

Mon NN, Kokuryo T, Hamaguchi M (2009). Inflammation and tumor progression: a lesson from TNF-alpha-dependent FAK signaling in cholangiocarcinoma. Methods Mol Biol, 512, 279-93.

Moore RJ, Owens DM, Stamp G, et al (1999). Mice deficient in tumor necrosis factor-alpha are resistant to skin carcinogenesis. Nat Med, 5, 828-31.

Pinlaor S, Prakobwong S, Hiraku Y, et al (2010). Reduction of periductal fibrosis in liver fluke-infected hamsters after longterm curcumin treatment. Eur J Pharmacol, 638, 134-41.

Robbs BK, Lucena PI, Viola JP (2013). The transcription factor NFAT1 induces apoptosis through cooperation with Ras/ Raf/MEK/ERK pathway and upregulation of TNF-alpha expression. Biochim Biophys Acta, 1833, 2016-28.

Ryu J, Ku BM, Lee YK, et al (2011). Resveratrol reduces TNFalpha-induced U373MG human glioma cell invasion through regulating NF-kappaB activation and uPA/uPAR expression. Anticancer Res, 31, 4223-30.

Song W, Tian L, Li SS, et al (2014). The aberrant expression and localization of prohibitin during apoptosis of human cholangiocarcinoma Mz-ChA-1 cells. FEBS Lett, 588, 422-8. 
Poom Adisakwattana et al

Srimunta U, Sawanyawisuth K, Kraiklang R, et al (2012). High expression of $\mathrm{ABCC} 1$ indicates poor prognosis in intrahepatic cholangiocarcinoma. Asian Pac J Cancer Prev, 13, 125-30.

Sripa B, Pairojkul C (2008). Cholangiocarcinoma: lessons from Thailand. Curr Opin Gastroenterol, 24, 349-56.

Srivatanakul P, Sriplung H, Deerasamee S (2004). Epidemiology of liver cancer: an overview. Asian Pac J Cancer Prev, 5 , 118-25.

Tachezy M, Zander H, Marx AH, et al (2012). ALCAM (CD166) expression and serum levels in pancreatic cancer. PLoS One, 7, 39018.

Tanimura Y, Kokuryo T, Tsunoda N, et al (2005). Tumor necrosis factor alpha promotes invasiveness of cholangiocarcinoma cells via its receptor, TNFR2. Cancer Lett, 219, 205-13.

Techasen A, Namwat N, Loilome W, et al (2014). Tumor necrosis factor-alpha modulates epithelial mesenchymal transition mediators ZEB2 and S100A4 to promote cholangiocarcinoma progression. J Hepatobiliary Pancreat Sci, 21, 703-11.

Wang SL, Li YX, Song YW, et al (2011). Triple-negative or HER2-positive status predicts higher rates of locoregional recurrence in node-positive breast cancer patients after mastectomy. Int J Radiat Oncol Biol Phys, 80, 1095-101.

Wiiger MT, Gehrken HB, Fodstad O, et al (2010). A novel human recombinant single-chain antibody targeting CD166/ ALCAM inhibits cancer cell invasion in vitro and in vivo tumour growth. Cancer Immunol Immunother, 59, 1665-74.

Wright GL, Jr., Haley C, Beckett ML, et al (1995). Expression of prostate-specific membrane antigen in normal, benign, and malignant prostate tissues. Urol Oncol, 1, 18-28.

Yonglitthipagon P, Pairojkul C, Chamgramol Y, et al (2010). Up-regulation of annexin A2 in cholangiocarcinoma caused by Opisthorchis viverrini and its implication as a prognostic marker. Int J Parasitol, 40, 1203-12.

Zhou JX, Li Y, Chen SX, et al (2011). Expression and prognostic significance of cancer-testis antigens (CTA) in intrahepatic cholagiocarcinoma. J Exp Clin Cancer Res, 30, 2.

Ziegler YS, Moresco JJ, Tu PG, et al (2014). Plasma membrane proteomics of human breast cancer cell lines identifies potential targets for breast cancer diagnosis and treatment. PLoS One, 9, 102341. 